\title{
Effects of natural and anthropogenic stressors on lysosomal destabilization in oysters Crassostrea virginica
}

\author{
Amy Huffman Ringwood ${ }^{1,2,3, *}$, Deanna E. Conners ${ }^{2,3}$, Jennifer Hoguet ${ }^{3}$ \\ ${ }^{1}$ Marine Resources Research Institute, 217 Fort Johnson Road, Charleston, South Carolina 29412, USA \\ ${ }^{2}$ Medical University of South Carolina, 171 Ashley Avenue, Charleston, South Carolina 29425, USA \\ ${ }^{3}$ University of Charleston, 66 George Street, Charleston, South Carolina 29424, USA
}

\begin{abstract}
Lysosomal destabilization indices (based on a neutral red retention assay) were evaluated for digestive gland cells of oysters Crassostrea virginica. Laboratory studies were conducted to evaluate the effects of variable salinity regimes (a natural stressor) and copper exposures (a pollutant stressor) on lysosomal destabilization. Field studies were also conducted with native oysters and hatcheryreared juvenile oysters deployed in situ at reference and polluted sites. Lysosomal integrity was not affected by either short-term or longer-term variations in salinity during laboratory experiments, and the destabilization indices were similar to those of deployed and native oysters from reference sites characterized by a range of salinities. However, laboratory Cu exposures (ranging from 2.5 to $20 \mu \mathrm{g} \mathrm{Cu}^{-1}$ ) caused significant adverse effects on lysosomal destabilization after only $18 \mathrm{~h}$, and the effects were sustained or worsened with increasing exposure tume and concentration. Hatchery-reared oysters deployed at or native oysters collected from polluted sites had significantly higher lysosomal destabilization indices. Estuarine habitats are characterized by variable salinity regimes, so cellular responses that are sensitive to salinity stress as well as contaminant stress would be difficult to interpret if salinity effects cannot be distinguished from pollutant effects. A robust biomarker of anthropogenic effects should be insensitive to natural stressors such as salinity, but should be sensitive to pollutants. The salinity and contaminant studies described in this paper indicate that lysosomal destabilization responses in oysters are insensitive to salinity variations and sensitive to pollutants, and are therefore potentially valuable biomarkers of anthropogenic stress.
\end{abstract}

KEY WORDS: Lysosomes - Neutral red assay · Bioindicators - Oysters Copper - Pollutants

\section{INTRODUCTION}

Estuaries provide critical feeding, spawning, and nursery habitats for numerous species, including commercially and recreationally important fish, shellfish, and waterfowl. The potential for increased stress in marine organisms due to anthropogenic pressures associated with increasing development in coastal zones (contaminant inputs, habitat alterations, etc.) demands careful monitoring of biological resources and development of strategies to minimize the impacts. The tools and analytical capabilities for documenting

\footnotetext{
•E-mail: ringwooda@mrd.dnr.state.sc.us
}

the presence of contaminants in marine habitats and bioaccumulation in organisms are well developed. However, the critical issue is determining if the organisms are adversely affected. Sediment contaminant analyses can document the presence of contaminants, but potential impacts on the biota are not readily predictable because bioavailability is a dynamic component composed of complex physical, chemical, and biological interactions. Likewise the accumulation of contaminants in tissues does not automatically indicate adverse effects since compensatory mechanisms may function to sequester, detoxify, or ameliorate the effects. Therefore tools are needed that will facilitate our ability to recognize when contaminant conditions adversely affect biotic integrity. Cellular and molecular 
indicators provide the greatest potential for identifying individuals and populations for which conditions have exceeded compensatory mechanisms and which are experiencing chronic stress, which if unmitigated may progress to severe effects at the ecosystem level.

Lysosomes are regarded as valuable indicators of pollutant-induced injury (Moore 1994). They are involved in numerous functions, including nutrition, tissue repair, cellular defense, and turnover of membranes, organelles, and proteins (Adema et al. 1991 , Auffret \& Oubella 1994). The acidic environment required for optimal activity of acid hydrolases involved in many functions is maintained by a membrane ATPase-dependent $\mathrm{H}^{+}$proton pump (Ohkuma et al. 1982). Lysosomes are also involved in sequestration and metabolism of toxins, and there is a substantial body of literature validating that environmental pollutants, organic xenobiotics and metals, cause destabilization of lysosomes in fish and molluscs (Lowe et al. 1981, 1995a, b, Moore 1982, 1985, 1994). Cytochemical investigations have shown that chemical contaminants can induce profound structural and functional alterations (Moore 1988, 1990, Regoli 1992). Membrane damage associated with impairment of the $\mathrm{H}^{+}$proton pump and leakage of enzymes such as B-glucuronidase into the cytoplasm may represent initial stages of damage which could progress to impairment of a variety of vital functions and cell death (Moore 1994, Lowe 1996).

Recently, techniques for assessing lysosomal destabilization using a relatively simple neutral red retention assay that utilizes live cells rather than fixed cells and histological techniques have been developed (Lowe et al. 1992, 1995a). This simple approach was developed in conjunction with fundamental histochemical studies. For this assay, cells are incubated in a neutral red suspension, and the lipophilic dye preferentially accumulates in the lysosomes where it is trapped by protonization. Stable lysosomes retain the dye for extended periods (several hours), whereas damaged lysosomes are unable to retain the dye so it leaks into the cytoplasm. Neutral red retention assays reflect the efflux of lysosomal contents into the cytosol that occurs when membranes are damaged and may also reflect impairment of the $\mathrm{H}^{+}$ion pump (Lowe et al. 1995b).

To date, bivalve studies have been conducted with mussels, Mytilus edulis and other Mytilus species. In this paper, studies are presented using these techniques with oysters Crassostrea virginica. Lysosomal responses following laboratory exposures to $\mathrm{Cu}$ and field exposures to contaminants are described. Another important parameter that was evaluated was salinity, since oysters live in habitats ranging from $8-10 \%$ to full seawater $(34 \%)$. If salinity variations af- fect lysosomal condition, then field studies on animals from variable salinity regimes must be carefully interpreted to distinguish anthropogenic causes from salinity effects. Therefore the results from these studies were used to evaluate 2 hypotheses regarding lysosomal responses in oysters: (1) lysosomal destabilization indices are not affected by salinity, and (2) lysosomal destabilization indices are affected by anthropogenic contaminants.

\section{MATERIALS AND METHODS}

Neutral red lysosomal destabilization assay. The neutral red (NR) retention assay was modified slightly from the protocols previously described (Lowe et al. 1992, Lowe \& Pipe 1994). Pieces of digestive glands of individual oysters (approximately $2 \mathrm{~mm}$ cubes) were incubated in calcium/magnesium free saline (CMFS, $20 \mathrm{mM}$ Hepes, $250 \mathrm{mM} \mathrm{NaCl}, 12.5 \mathrm{mM} \mathrm{KCl}, 5 \mathrm{mM}$ EDTA, adjusted to pH 7.3 with $\mathrm{NaOH}$ ) in trypsinizing flasks on a shaker for $20 \mathrm{~min}$ to initially disaggregate the cells. Trypsin $\left(0.4 \mathrm{mg} \mathrm{ml}^{-1}\right)$ was then added to each flask and shaken for an additional 20 min to complete the disaggregation of the cells. Cell suspensions were filtered through $100 \mu \mathrm{m}$ nylon mesh and centrifuged $\left(1500 \mathrm{rpm}, 5 \mathrm{~min}, 10^{\circ} \mathrm{C}\right)$. The supernatant was discarded and cells were washed twice and resuspended in CMFS. An aliquot of the cell suspension $(40 \mu \mathrm{l})$ was mixed with a $40 \mu \mathrm{l}$ aliquot of NR (prepared from a $4 \mathrm{mg}$ $\mathrm{ml}^{-1}$ stock solution of NR in distilled water and diluted with CMFS to a $40 \mu \mathrm{g} \mathrm{ml}^{-1}$ working solution immediately prior to the assay) on a microscope slide, covered with a cover slip, and incubated in a humidity chamber at room temperature $\left(23-25^{\circ} \mathrm{C}\right)$ for $60 \mathrm{~min}$. Digestive gland cells ( 6 to $12 \mu \mathrm{m}$ in diameter) containing lysosomes were examined with a light microscope $(100 \times$ under oil immersion) to evaluate NR retention (reading time for each slide was virtually the same, $<1.5 \mathrm{~min}$ ). Cells with NR retained in lysosomes were scored as stable and those with NR leaking into the cytoplasm were scored as destabilized. A minimum of 50 cells was counted for each preparation, and the data were expressed as a lysosomal destabilization index, i.e. percentage of cells with destabilized lysosomes per oyster.

Laboratory studies. Laboratory studies were conducted to evaluate the effects of variable salinity regimes (a natural stressor) and copper exposures (a pollutant stressor) on destabilization of lysosomes. For the salinity studies, oysters ( 3 to $5 \mathrm{~cm}$ in height) were collected from a clean site characterized by approximately $25 \%$ salinity (a substantial body of salinity data from this site, including continuous readings from a Datasonde unit deployed in situ for up to a week, indi- 
cate that salinity at this site is relatively constant, ranging from 25 to $28 \%$ o. Upon return to the laboratory, the oysters were separated and immediately placed in 4 salinity treatments $(10,20,25$, and $30 \%)$. Oysters were maintained in the laboratory (initial concentration of 30 to 40 oysters per $12 \mathrm{l}$; the water was changed and animals were fed a phytoplankton mixture of Chaetocerus gracilis and Isochrysis galbana, $20 \mathrm{ml}$ per oyster, every third day). Lysosomal destabilization assays were conducted after $18 \mathrm{~h}$ to determine the effects of a relatively sudden change in salinity, and periodically over the next 2 wk $(4,7$, and 14 d) to determine the longer-term responses. At the end of each time period, 5 individuals were removed and processed for the NR lysosomal destabilization assay.

The copper exposure experiments were conducted in a similar manner. Oysters collected from a clean site were exposed to a range of copper concentrations $(0$, $2.5,5.0,10.0$, and $20.0 \mathrm{\mu g} \mathrm{l}^{-1}$ ) at $25 \%$. Oysters from each treatment were sampled after $18 \mathrm{~h}, 4 \mathrm{~d}, 7 \mathrm{~d}$, and $14 \mathrm{~d}$ to evaluate short-term as well as more sustained responses to $\mathrm{Cu}$.

The copper concentrations of digestive gland tissues were determined for oysters after $14 \mathrm{~d}$ of treatment. Digestive gland tissues were pooled from 3 to 4 individuals, dried and weighed, digested with concentrated nitric acid, and analyzed by graphite furnaceAAS. The results werc cxprossed as $\mu \mathrm{g} \mathrm{Cu} \mathrm{g}^{-1}$ dry tissue weight. Four replicate samples were analyzed for each treatment, and means and standard deviations were computed. Standard reference materials (NIST Oyster Tissue, 1566a; expected $\mathrm{Cu}$ concentration 66.3 $\pm 4.3 \mathrm{\mu g} \mathrm{g}^{-1}$ ) were analyzed to verify measurements. The mean measured concentration of standard material was $66.6 \pm 5.9 \mu \mathrm{g} \mathrm{g}^{-1}$.

Mean destabilization indices and standard deviations were computed for each treatment, and statistical analyses were conducted using Sigma Stat. Analysis of variance (ANOVA) and an a posteriori test (StudentNewman-Keuls method, SNK) were used to identify treatments that were significantly different from the controls. All analyses passed normality and equal variance tests, so although arcsine transformations were not required the transformed data were analyzed and the results were the same. Regression analyses were used to evalute the relationships between lysosomal destabilization indices and $\mathrm{Cu}$ concentrations. The regression analyses passed normality and homoscedasticity tests.

Field studies. Juvenile oysters, cultured at the bivalve culture facilities at the Marine Resources Research Institute (MRRI, Charleston, SC, USA), were deployed at 15 sites in South Carolina estuaries for approximately $30 \mathrm{~d}$ from mid-May to mid-June 1996. Most of these sites have been well-characterized with regard to contaminant loadings as part of the Environmental Monitoring and Assessment Pragram (EMAP) in the Carolinian Province, and others were characterized as part of the Bivalve Biomarker Project. Sediment samples collected as part of the Bivalve Biomarker Project for these studies were analyzed for metals, PAHs, pesticides, and PCBs by staff at the National Marine Fisheries Service, Southeast Fisheries Science Center, Charleston Laboratory (Dr. Geoff Scott, Chief, Marine Ecotoxicology Division). Rigorous quality control measures were included to ensure the validity of the data, including analysis of standard reference materials (NIST 1941, Organics in Marine Sediments; NRB Canada MESS-2, Metals in Marine Sediments). The percent recovery for Cu was $90 \%$.

At the end of the deployment period, oysters were retrieved, washed free of mud and debris, and depurated in seawater collected from the site (oxygenated, $22^{\circ} \mathrm{C}$ ) for $24 \mathrm{~h}$. Specimens were then removed from the water and held in plastic bags in the refrigerator until processed for lysosomal destabilization ( $\mathrm{n}=20$ individuals for each site). As part of our standard operating procedures, all individuals were processed within $2 \mathrm{~d}$ of depuration, and oysters from each site were subdivided so that half were assayed on the first day and the other half on the second day. Statistical analyses (i.e. Student's t-tests) of oysters assayed on Day 1 and Day 2 were not significantly different from each other (these results corroborate similar analyses from a more extensive dataset covering longer holding times), indicating that lysosomal integrity was not affected by the $2 \mathrm{~d}$ holding time. Mean percent lysosomal destabilization and standard deviations were computed for each site. ANOVA and SNK were used to identify treatments that were significantly different from the controls. The analyses passed normality and equal variance tests

The concentrations of $\mathrm{Cu}$ in the tissues (total soft tissues, 5 replicates, tissues pooled from 10 to 20 individuals for each replicate) of deployed oysters were determined by flame AAS. Standard reference materials (NIST Oyster Tissue, 1566a; expected Cu concentra-

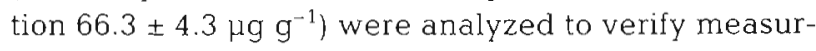
ments. The mean measured concentration of standard material was $67.6 \pm 8.3 \mu \mathrm{kg} \mathrm{g}^{-1}$. Regression analyses were used to evalute the relationships between lysosomal destabilization and sediment $\mathrm{Cu}$ concentrations as well as tissue $\mathrm{Cu}$ concentrations. Studentized residuals were used to identify potential outliers, and those that were statistically significant (based on a table of critical values for tests of discordancy) were removed (Barnett \& Lewis 1978). All analyses passed normality and homoscedasticity tests.

Native oysters were also collected from many of the sites where hatchery-reared juveniles were deployed 
(10 of the 15 sites), and the effects on lysosomal destabilization were determined $n=15$ individuals for each site). These data facilitated consideration of how well the deployed oyster results reflected the conditions of native oysters. Data from the reference, unpolluted sites were aiso used to consider the effects of variable salinity regimes on lysosomal destabilization rates under field conditions. Mean destabilization indices and standard deviations were computed for each site, and ANOVA (data passed normality and equal variance tests) and SNK were used to identify sites that were significantly different from reference sites.

\section{RESULTS}

\section{Salinity studies}

There were no significant effects of any of the salinity treatments on lysosomal destabilization, in either the short-term or long-term responses (Fig. 1). Although sudden or longer-term changes in salinity may elicit an array of homeostatic responses involved in osmoregulation, there was no evidence from these laboratory studies that salinity changes affected lysosomal membrane integrity. Lysosomal destabilization indices over all salinity treatments ranged from 16.24 to 24.36 . Oysters (both deployed and native) collected from field reference sites (with salinities ranging from 22 to $32 \%$ ) also had similar destabilization indices (ranging from 18.30 to $24.95 \%$ ), consistent with the laboratory studies

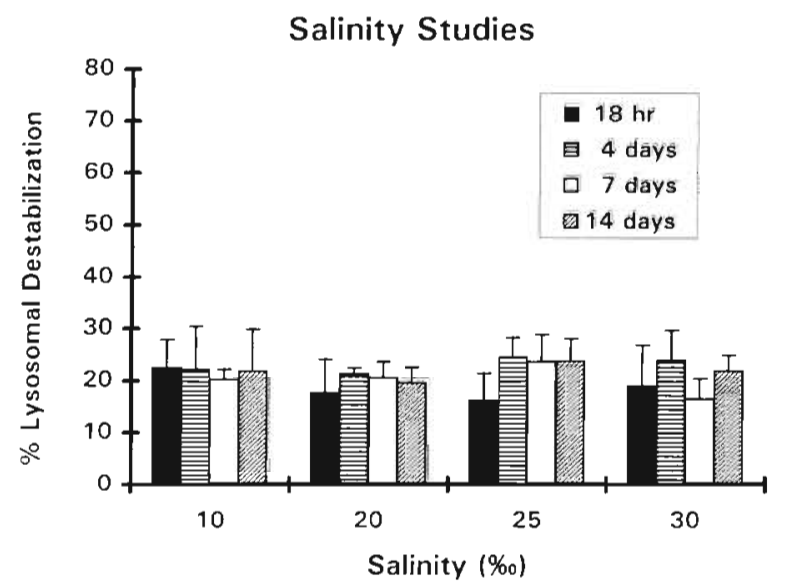

Fig. 1. Crassostrea virginica. Effects of various salinity regimes on lysosomal stability. Oysters were collected from a reference site, maintained in the laboratory at various salinities and sampled at the specified time intervals. Data are means $+\mathrm{SD}$ ( $\mathrm{n}=5$ individuals). No significant differences between treatments were detected

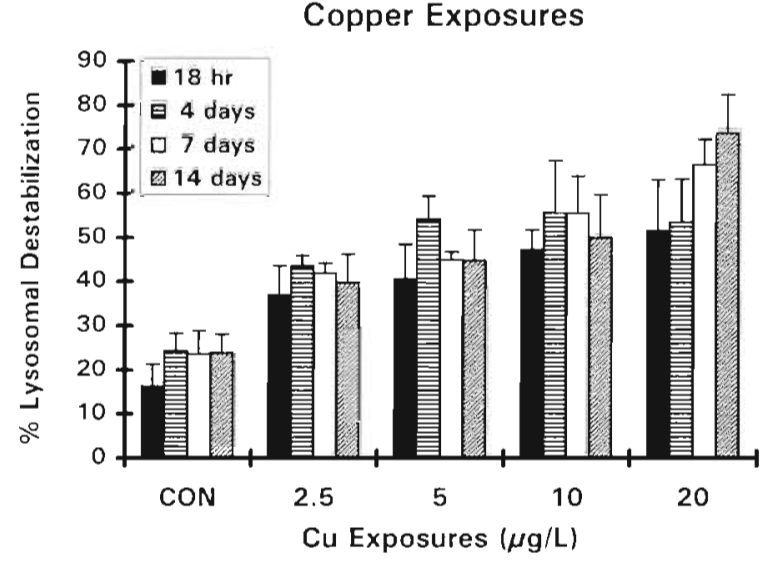

Fig. 2. Crassostrea virginica. Effects of copper exposures on lysosomal stability. Oysters were collected from a reference site, maintained in the laboratory at various $\mathrm{Cu}$ concentrations (salinity $25 \%$ ) and sampled at the specified time intervals. Data are means $+S D(n=5$ individuals). All $\mathrm{Cu}$ treatments were significantly different $(p<0.05)$ from the controls

\section{Laboratory $\mathrm{Cu}$ exposures}

When oysters were exposed to $\mathrm{Cu}$, using the same experimental design as the salinity experiments, significant adverse effects on lysosomal destabilization were observed after only $18 \mathrm{~h}$ for the range of $\mathrm{Cu}$ concentrations tested (2.5 to $20.0 \mathrm{\mu g} \mathrm{l}^{-1}$ ) (Fig. 2). The effects were sustained or worsened with increasing exposure time and concentration. The mean concentrations of $\mathrm{Cu}$ accumulated in digestive gland tissues after $14 \mathrm{~d}$ were highly correlated with exposure concentration (Fig. 3). The mean lysosomal destabilization indices after $14 \mathrm{~d}$ of $\mathrm{Cu}$ exposure were also highly correlated with exposure concentration $\left(R^{2}=0.94\right)$ and mean tissue concentrations (Fig. 4).

\section{Field studies - deployed and native oysters}

Hatchery-reared juvenile oysters were deployed at the sites listed in Table 1. Sites were classified a priori as reference or degraded based on nearby inputs as well as existing sediment contaminant data. Information on site location, salinity, temperature, $\mathrm{pH}$, and the number of contaminants that exceeded ER-L levels (sediment quality guidelines defined by Long et al. 1995) are listed in Table 1. Significant increases in lysosomal destabilization indices were observed in oysters deployed at all but 1 potentially degraded site (Kiawah Creek) (Fig. 5). Likewise, studies with native adults reflected the deployed oyster results, i.e. significantly higher destabilization indices were observed in oysters collected from all degraded sites except Kiawah Creek. 


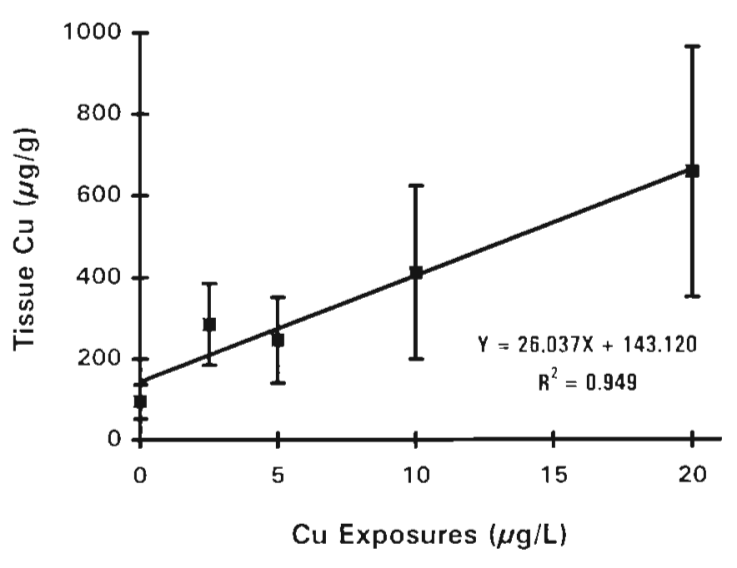

Fig. 3. Crassostrea virginica. Relationship between $\mathrm{Cu}$ exposure concentrations and $\mathrm{Cu}$ accumulated in digestive gland tissues after $14 \mathrm{~d}$ exposures to $0,2.5,5,10$, and $20 \mu \mathrm{g} \mathrm{Cu} \mathrm{l}^{-1}$ Values are means ( \pm SD) of 4 replicate composites ( 3 to 4 individuals per composite) for each treatment. Regression parameters are shown; standard errors for the coefficient and constant were 3.5 and 35.8 , respectively

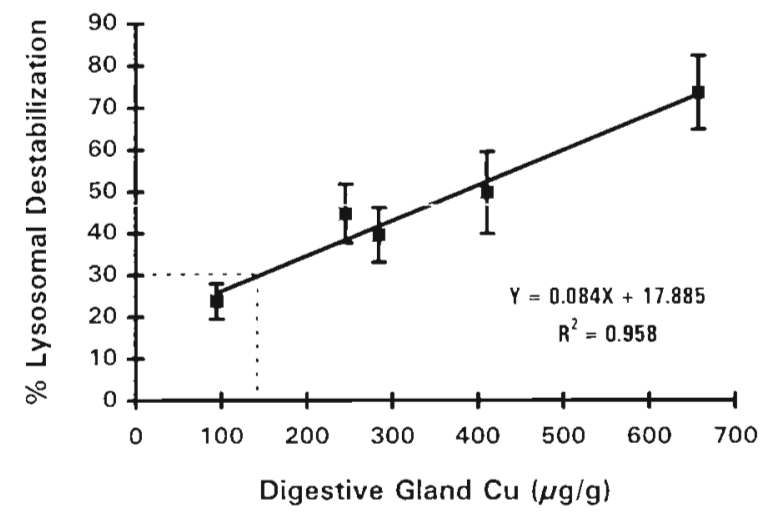

Fig. 4. Crassostrea virginica. Relationship between $\mathrm{Cu}$ concentrations of digestive gland tissues and lysosomal destabilization indices of digestive gland cells after $14 \mathrm{~d}$ of exposure to $0.25,5,10$ and $20 \mu \mathrm{g} \mathrm{Cu} \mathrm{l}^{-1}$. Regression parameters are shown; standard errors for the coefficient and constant were 0.01 and 3.9 , respectively

The concentrations of $\mathrm{Cu}$ in the soft tissues of deployed oysters was highly correlated with $\mathrm{Cu}$ concentrations in the sediments $\left(\mathrm{R}^{2}=0.69 ; \mathrm{p}<0.0001\right)$. Lysosomal destabilization indices were significantly correlated with either $\mathrm{Cu}$ compartment, but the relationship was slightly stronger for tissue Cu concentrations (Fig. 6). Shipyard Creek (SPY) was identified as a statistically significant outlier in both cases. A strong relationship between lysosomal destabilization indices in native oysters and sediment $\mathrm{Cu}$ concentrations was also observed $(y=0.59 x+$ 16.86; $\mathrm{R}^{2}=0.67 ; \mathrm{n}=8$ sites, SPY and TRT were identified as outliers based on studentized residuals).

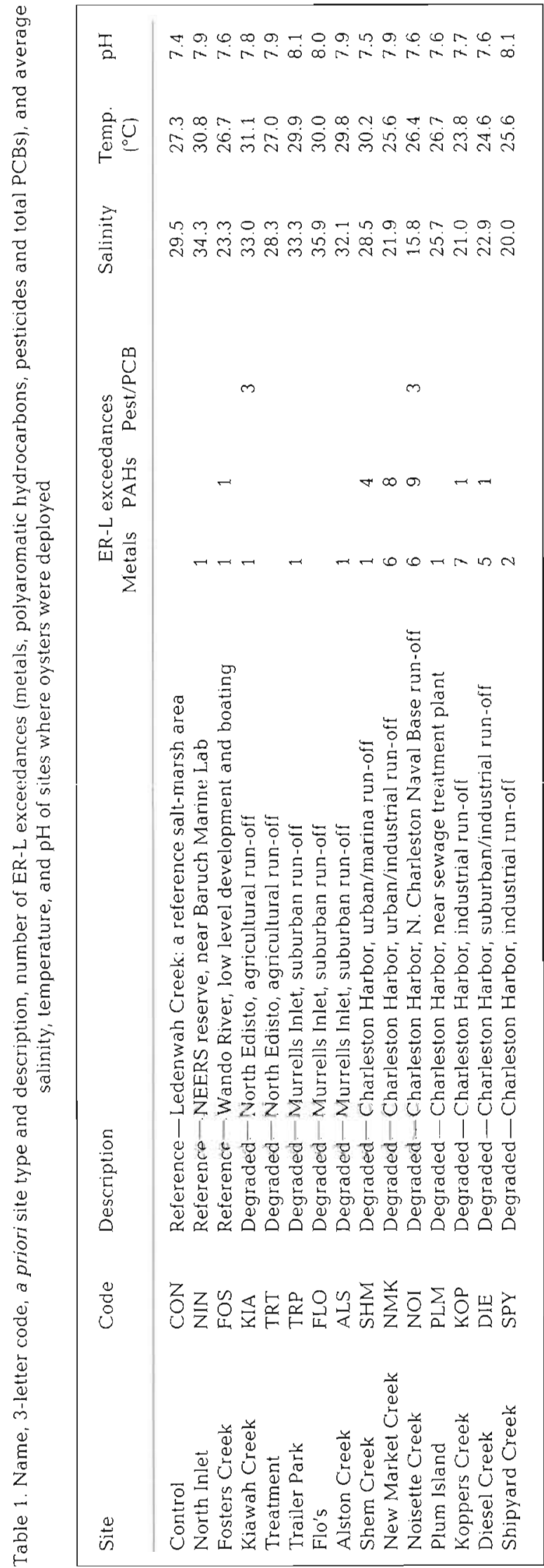




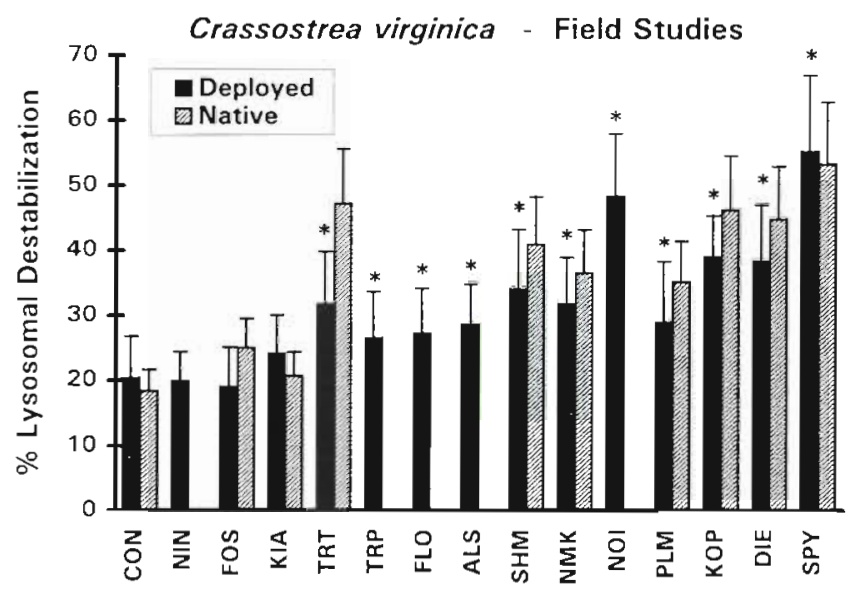

Fig. 5. Crassostrea virginica. Lysosomal destábilization indices of hatchery-reared juvenile oysters ( $\mathrm{n}=20$ individuals) deployed in situ for $1 \mathrm{mo}$ and native oysters ( $\mathrm{n}=15$ individuals). See Table 1 for site information. Data are means + SD.

"Site was significantly different from the reference sites

\section{DISCUSSION}

The neutral red assay was evaluated using oyster digestive gland cells, and the results continued to support lysosomal integrity indicators as potentially valuable biomonitoring tools for estuarine species. The laboratory salinity studies as well as analyses of native or deployed oysters from variable salinity regimes indicated that lysosomal integrity was not affected by either short-term or longer-term variations in salinity. However, laboratory $\mathrm{Cu}$ exposures and studies with native and deployed oysters from polluted sites indicated that lysosomal destabilization rates were sensitive to contaminant stress. Estuarine habitats are characterized by variable salinity regimes, so if cellular responses are sensitive to salinity stress as well as contaminant stress, the results would be difficult to interpret if salinity effects could not be distinguished from. pollutant effects. A 'good' biomarker of anthropogenic effects should be insensitive to natural stressors such as salinity, but should be sensitive to pollutants. In combination, the salinity and contaminant studies indicated that Iysosomal destabilization responses in oysters are potentially valuable biomarkers of pollutant stress.

Significant increases in lysosomal destabilization were observed with the range of $\mathrm{Cu}$ concentrations tested (2.5 to $20 \mu \mathrm{g} \mathrm{l}^{-1}$ ), and destabilization indices were highly correlated with the Cu accumulated in digestive gland tissues. Significantly higher percentages of cells with destabilized lysosomes were detectable within $24 \mathrm{~h}$ of $\mathrm{Cu}$ exposure. Lysosomal membrane destabilization after a $1 \mathrm{~d}$ exposure to low
$\mathrm{Cu}$ concentrations has been reported in mussels (Viarengo 1989), consistent with the results reported here for oysters. At the highest concentration of $\mathrm{Cu}$ tested $\left(20 \mu \mathrm{g} \mathrm{I}^{-1}\right)$, lysosomal destabilization indices increased with time, but at the lower concentrations, destabilization tended to plateau or improve slightly. There was a trend of improvement between Days 4 and 7 of exposure, suggesting that compensatory mechanisms may be ameliorating somewhat the effects of $\mathrm{Cu}$. This time frame is typical of the delay associated with induction of metallothioneins in bivalves (Viarengo et al. 1981, Roesijadi \& Klerks 1989, Ringwood et al. in press), which could sequester some portion of excess $\mathrm{Cu}$, thereby reducing the potential for further damage.
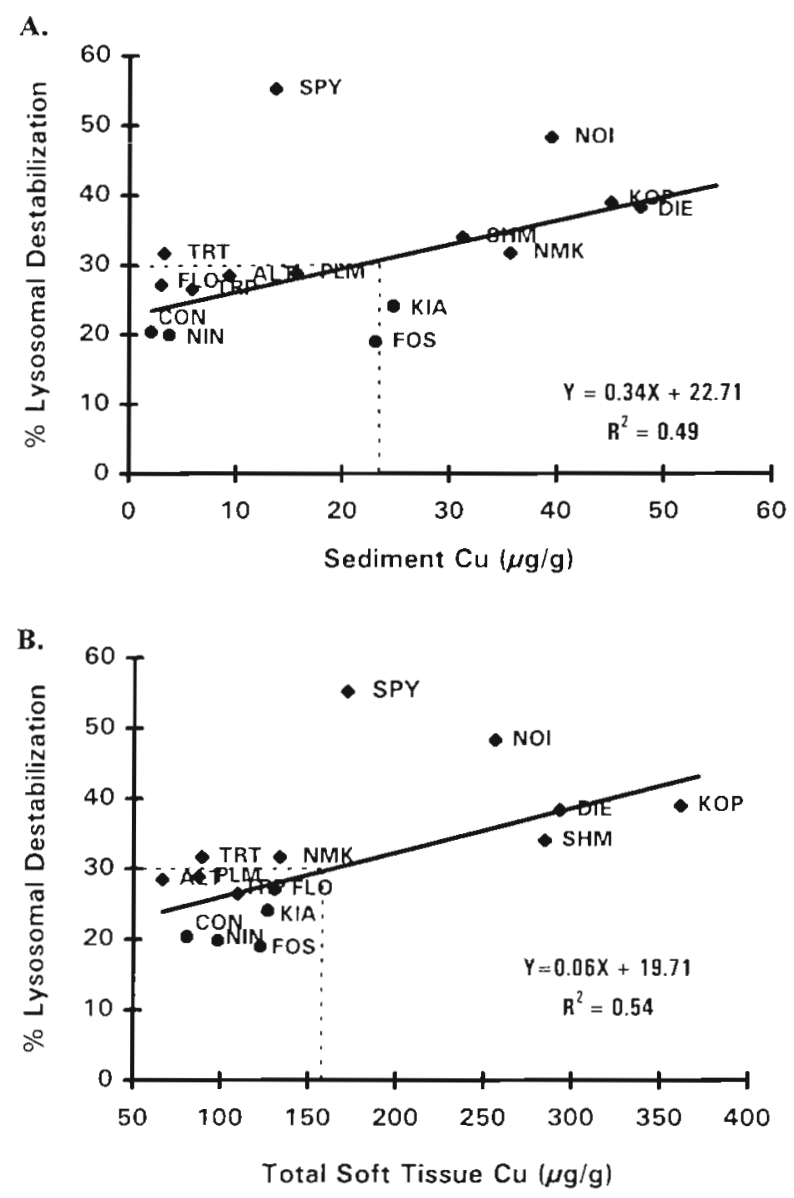

Fig. 6. Crassostrea virginica. Relationships between $\mathrm{Cu}$ concentrations of sediments (A) and tissues (B) and lysosomal destabilization indices of digestive gland cells of hatcheryreared juvenile oysters deployed in situ for 1 mo. Regression parameters are shown. Sites designated with circles did not have significantly higher destabilization rates; those indicated by diamonds were significantly different from. reference sites 
Important issues regarding the use of cellular biomarkers include understanding the effects of natural stressors and developing an adequate database for defining normal ranges. The ability to identify polluted sites is dependent on our ability to distinguish normal from perturbed responses. The potential variability associated with the effects of environmental factors that may fluctuate normally must be appreciated (Huggett et al. 1992). In these studies, laboratory and field investigations indicated that lysosomal destabilization indices were not affected by salinity. Consistent with our results, previous studies conducted by Moore et al. (1980) with Mytilus edulis indicated no significant changes in lysosomal enzyme activities in mussels acclimated to a high salinity regime (i.e. $33 \%$ ) and then transferred to a low salinity regime (i.e. $15 \%$ ). However, short-term alterations in the activity of lysosomal enzymes were observed in the reciprocal experiment (i.e. from low to high salinity), suggesting that enzyme changes could be related to mobilization of amino acids for osmoregulation (Moore et al. 1980). Although salinity changes may be expected to elicit enzyme alterations, our studies with oysters suggest that any changes in enzyme responses did not result in significant damage to lysosomal integrity.

There is some evidence that lysosomal destabilization may also not be affected by environmentally relevant temperatures since control rates of oysters measured from spring studies were not significantly different from those conducted during summer months. Furthermore, height data were also collected as part of the standard processing procedures, and no significant correlations $\left(\mathrm{R}^{2}=0.0006 ; \mathrm{n}=114\right.$; based on juveniles and adults from various reference sites that ranged from 2 to $9 \mathrm{~cm}$ in height) between size and lysosomal destabilization of oysters were detected. Our current database for reference oysters (hatcheryreared, wild populations, laboratory and field experiments) indicates normal basal lysosomal destabilization rates that were consistently in the range 15 to $25 \%$.

Significantly higher destabilization indices, particularly those $>30 \%$, were always associated with anthropogenic stress. Although statistical significance was sometimes detected when destabilization indices were between 25 and $30 \%,>30 \%$ may be a better overall estimate of biological significance. If the $30 \%$ criterion is applied to the laboratory and field data (Figs. $4 \& 6$ ), then concentrations in sediments or tissues that would reflect the potential for perturbed lysosomal responses could be estimated. These studies suggest that when tissue $\mathrm{Cu}$ concentrations exceed 150 to $200 \mu \mathrm{g} \mathrm{g}^{-1}$, significant adverse effects on lysosomal functions would be expected. On the basis of sediment concentrations, destabilization indices $>30 \%$ were predicted when $\mathrm{Cu}$ concentrations exceeded $23 \mu \mathrm{g} \mathrm{g}^{-1}$ (approximately the same estimate was derived whether deployed or native oyster data were used). This concentration is slightly lower than the ER-L value of $34 \mu \mathrm{g} \mathrm{g}^{-1}$ reported by Long et al. (1995). Certainly, other pollutants in addition to $\mathrm{Cu}$ would contribute to adverse effects. For example, at Shipyard Creek, destabilization rates were high although $\mathrm{Cu}$ concentrations were low. Shipyard Creek contains some of the highest chromium concentrations measured worldwide (Hyland et al. 1996). The differences between Fig. 6A and 6B probably reflect bioavailability to some extent. For example, the high Cu concentrations in the sediments of NMK functioned as an excellent predictor of lysosomal damage, but relatively low concentrations were found in oyster tissues. Therefore, some other contaminants probably played important roles in the responses of NMK oysters. The good correlation for sediments suggests that sediment Cu concentrations served as a good surrogate of overall contamination. Evaluations of the relationships between lysosomal destabilization indices and other measured contaminants are in progress.

Another important issue regarding cellular biomarkers is to establish if a response indicates exposure or effects. Although alterations in a response may occur as a result of exposure, bivalves and other estuarine organisms may activate compensatory mechanisms that ameliorate adverse effects. Therefore it is impor tant to distinguish exposure and successful homeostatic responses from responses that indicate cellular toxicity and reduced fitness. The significant increases in lysosomal destabilization indices in less than $24 \mathrm{~h}$ indicate that effects can be detected readily as a result of exposure. Lysosomal destabilization responses may function as valuable early warning signals, one of cells' first responders to perturbations, or indicators of chronic damage. It is important to identify what levels of lysosomal destabilization can be sustained before adverse effects on growth and reproduction are realized, or when deleterious conditions reflect progression to a 'point of no return' or irreversible damage. The use of a suite of responses such as lipid peroxidation, glutathione, etc. in conjunction with lysosomal function studies would improve interpretation and confidence in our assessments.

The endpoint used in these studies (\% lysosomal destabilization after $60 \mathrm{~min}$ ) was different from the latency response previously used for the neutral red retention assay (Lowe et al. 1992). However, this approach was adopted for several reasons. From a careful review of many of the studies published using the neutral red assay, it was found that, in animals exposed to pollutants in either laboratory or field settings, the latency period was typically less than 60 min, whereas control animals or animals from reference 
sites had latency periods in the range of 2 to $3 \mathrm{~h}$ (Lowe et al. 1992, 1995a, b, Lowe \& Pipe 1994). It was therefore our opinion that, in these studies, a 60 min assay would result in the identification of site-specific or treatment-specific differences that would be consistent with the latency period approach. Also, using a $60 \mathrm{~min}$ fixed interval results in a shorter processing time so a greater number of samples can be processed in less time. Minimizing processing time is an important attribute for incorporating an assay as part of a monitoring program.

Fortunately, this relatively simple approach is empowered by the extensive previous studies with mussels and fish that have established an appreciation of the mechanisms and ramifications of lysosomal destabilization. In mussels, other associated changes included increased activation of lysosomal proteolytic enzymes and stimulation of lipid peroxidation as evidenced by increased lipofuscin content (Viarengo et al. 1990). Two primary functions of molluscan digestive cells are heterophagy and digestion of food material, and autophagy of cellular components. If fusion and enzymatic processes are perturbed, nutritional functions may be impaired and the normal autophagy to heterophagy balance may be disturbed (Moore 1994). Impacts on fitness at the organismal level have also been demonstrated. Increased digestive cell atrophy and lysosomal disturbances have been associated with reduced scope for growth in mussels (Lowe et al. 1981, Moore \& Lowe 1985). Significant alterations in hepatic lysosomal destabilization occurred with the onset of early necrotic changes that increased as the incidence of tumors increased in flounder (Köhler \& Pluta 1995). A review of the numerous pertinent studies regarding the consequences of lysosomal damage is beyond the scope of this paper, but the preponderance of evidence continues to support the value of lysosomal indices as indicators of stress.

In conclusion, this study supports the continued development and implementation of lysosomal. destabilization indicators in oysters as monitoring tools. Although oysters tend to live in habitats that are more variable with regard to salinity regimes than mussels, lysosomal responses were not affected by salinity. Significant adverse effects were observed in response to contaminants in both field and laboratory settings. Continued evaluation of the significance of lysosomal responses in oysters in the context of a suite of physiological and cellular biomarkers will extend our interpretive capabilities

Acknowledgements. We gratefully acknowledge J. Hameedi and the NOAA. (National Oceanic and Atmospheric Administration, Office of Ocean Resources Conservation and Assess- ment), who provided funding for these studies (Cooperative Agreement No. NA57OA0486), Charles Keppler and Marianne Armstrong-Taylor of MRRI for their valuable assistance with many aspects of this study, and Geoff Scott and Dan Bearden of the NMFS, Charleston, South Carolina, for the sediment contaminant analyses and other general assistance with these studies.

\section{LITERATURE CITED}

Adema CM, Van der Knaap WPW. Sminia T (1991) Molluscan hemocyte-mediated cytotoxicity: the role of reactive oxygen intermediates. Rev Aquat Sci 4:201-223

Auffret M, Oubella R (1994) Cytometric parameters of bivalve molluscs: effect of environmental factors. In: Stolen JS, Fletcher TC (eds) Modulators of fish immune responses. SOS Publications, Fairhaven, NJ, p 23-32

Barnett V, Lewis I (1978) Outliers in statistical data. John Wiley \& Sons, Chichester

Huggett RJ, Kimerle RA, Mehrle PM, Bergman HL (1992) Biomarkers: biochemical, physiological, and histological markers of anthropogenic stress. Lewis Publishers, Boca Raton

Hyland JL, Herrlinger TJ, Snoots TR, Ringwood AH, Van Dolah RF, Hackney CT, Nelson GA, Rosen JS, Kokkinakis SA (1996) Environmental quality of estuaries of the Carolinian province: 1994. NOAA Technical Memorandum NOS ORCA 97

Köhler A, Pluta HJ (1995) Lysosomal injury and MFO activity in the liver of flounder (Platichthys flesus L.) in relation to histopathology of hepatic degeneration and carcinogenesis. Mar Envir on Res 39:255-260

Long ER, MacDonald DD, Smith SL, Calder FD (1995) Incidence of adverse biological effects within ranges of chemical concentrations in marine and estuarine sediments. Environ Manag 19:81-97

Lowe DM (1996) Mechanisms of toxicity in molluscan lysosomes. Mar Environ Res 42:109

Lowe DM, Fossato VU, Depledge MH (1995b) Contaminantinduced lysosomal membrane damage in blood cells of mussels Mytilus galloprovincialis from the Venice Lagoon: an in vitro study. Mar Ecol Prog Ser 129:189-196

Lowe DM, Moore MN, Clark KR (1981) Effects of oil on digestive cells in mussels: quantitative alterations in cellular and lysosomal structure. Aquat Toxicol 1:213-226

Lowe DM, Moore MN, Evans BM (1992) Contaminant impact on interactions of molecular probes with lysosomes in living hepatocytes from dab Limanda limanda. Mar Ecol Prog Ser 91:135-140

Lowe DM, Pipe RK (1994) Contaminant induced lysosomaI membrane damage in marine mussel digestive cells: an in vitro study. Aquat Toxicol 30:357-365

Lowe DM, Soverchia C, Moore MN (1995a) Lysosomal membrane responses in the blood and digestive cells of mussels experimentally exposed to fluoranthene. Aquat Toxicol 33:105-112

Moore MN (1982) Lysosomes and environmental stress. Mar Pollut Bull 13:42-43

Moore MN (1985) Cellular responses to pollutants. Mar Pollut Bull 16:134-139

Moore MN (1988) Cytochemical responses of the lysosomal system and NADPH-ferrihemoprotein reductase in molluscan digestive cells to environmental and experimental exposure to xenobiotics. Mar Ecol Prog Ser 46:81-89

Moore MN (1990) Lysosomal cytochemistry in marine environmental monitoring. Histochem J 22:187-191 
Moore MN (1994) Reactions of molluscan lysosomes as biomarkers of pollutant-induced cell injury. In: Renzoni A, Mattei N, Lorena L, Fossi MC (eds) Contaminants in the environment. A multidisciplinary assessment of risks to man and other organisms. CRC Press, Lewis Publishers, Boca Raton, p 111-123

Moore MN, Koehn RK, Bayne BL (1980) Leucine aminopeptidase (aminopeptidase-l), $n$-acetyl- $\beta$-hexosaminidase and lysosomes in the mussel, Mytilus edulis $\mathrm{L}$, in response to salinity changes. J Exp Zool 214:239-249

Moore MN, Lowe DM (1985) Cytological and cytochemical measurements. In: Bayne BL and 9 others (eds) The effects of stress and pollution on marine animals. Praeger Scientific, New York, p 179-204

Ohkuma S, Moriyama Y, Takano T (1982) Identification and characterization of a proton pump on lysosomes by fluoroscein isothiocyanate-dextran fluorescence. Proc Natl Acad Sci USA 79:2758-2762

Regoli F (1992) Lysosomal responses as a sensitive stress

Editorial responsibility: Otto Kinne (Editor),

Oldendorf/Luhe, Germany index in biomonitoring heavy metal pollution. Mar Ecol Prog Ser 84:63-69

Ringwood AH, Conners DE, Dinovo AA (in press) The effects of copper exposures on cellular responses in oysters. Mar Environ Res

Roesijadi G, Klerks PL (1989) Kinetic analysis of cadmium binding to metallothionein and other intracellular ligands in oyster gills. J Exp Zool 251:1-12

Viarengo A (1989) Heavy metals in marine invertebrates: mechanisms of regulation and toxicity at the cellular level. Aquat Sci 1:295-317

Viarengo A, Canesi L, Pertica M, Polj G, Moore MN, Orunesu $M$ (1990) Heavy metal effects on lipid peroxidation in the tissues of Mytilus galloprovincialis Lam. Comp Biochem Physiol 9C:37-42

Viarengo A, Pertica M, Mancinelli G, Palmero S, Zanicchi G, Orunesu M (1981) Synthesis of Cu-binding proteins in different tissues of mussels exposed to the metal. Mar Pollut Bull 12:347-350

Submitted: September 25, 1997; Accepted: December 23, 1997 Proofs received from author(s): May 7, 1998 